\title{
ANÁLISE COMPARATIVA DOS PLANOS DIRETORES DE ARBORIZAÇÃO ENQUANTO INSTRUMENTO DE PLANEJAMENTO E GESTÃO
}

Patrícia Mara Sanches ${ }^{1}$, Juliana Amorim da Costaํㄹ Demóstenes Ferreira da Silva Filho ${ }^{3}$

(recebido em 03.11.2008 e aceito para publicação em 18.12.2008)

\section{RESUMO}

A arborização das cidades brasileiras é marcada por falta de planejamento que resulta em um cenário de conflitos e baixa qualidade ambiental do espaço urbano. Portanto, faz-se necessária a utilização de instrumentos que normatizem e regularizem as atividades relacionadas à implantação e manejo da arborização viária. Um desses instrumentos é o Plano Diretor de Arborização Urbana (PDAU). Esse plano se constitui numa eficaz ferramenta tanto de planejamento como de guia para a manutenção e monitoramento da arborização urbana. Desta maneira, o estudo de Planos que já foram elaborados ou que estão em fase de elaboração é de grande importância para subsidiar a criação de novos para outras cidades. Neste trabalho foram analisados os Planos Diretores de Arborização das cidades de Porto Feliz/SP, Goiânia/GO, Vitória/ES e Porto Alegre/RS. Esta análise foi comparativa, possibilitando uma visão crítica de todos os aspectos e etapas que compõem o PDAU, gerando discussões e embasamento para futuros planos diretores.

Palavras-chave: plano diretor de arborização urbana, planejamento urbano, silvicultura urbana.

\footnotetext{
${ }_{1}^{1}$ Arquiteta e Urbanista, mestranda em Paisagem e Ambiente - FAU-USP, Endereço: Rua do Lago, 876, 05508.080, São Paulo - SP - Brasil, <patricia.msanches@usp.br>;

2 Gestora Ambiental, mestranda em Conservação de Ecossistemas Florestais - ESALQ-USP, Piracicaba-SP, <jcosta@esalq.usp.br>;

${ }^{3}$ Engenheiro Agrônomo, professor do Curso de Engenharia Florestal - ESALQ-USP, Piracicaba-SP, <dfsilva@esalq.usp.br>.
} 


\title{
COMPARATIVE ANALISES OF URBAN FOREST MASTER PLANS AS TOOLS FOR PLANNING AND MANAGEMENT
}

\begin{abstract}
The street tree planning in Brazilian cities is marked by lack of planning what results in many failures and an enviromental poor quality of the urban space Therefore, it is necessary to use tools that set standards and regulate the activities related to the establishment and management of urban forest. One of these instruments is the Urban Forest Master Plan. This plan is an effective tool in planning and a guide for the maintenance and monitoring of urban forest. Thus, the study of the plans that have already been developed or are under development have a great importance to guide and support the creation of new plans for other cities. In this paper the Urban Forest Master Plan of Porto Feliz/SP, Goiânia/GO, Vitória/ES and Porto Alegre/RS cities were analyzed comparatively. Such analyses provided a critical view of all aspects and steps of the master plans, helping the authorities in developing new plans.
\end{abstract}

Keywords: urban forest master plan, urban planning and urban forestry. 


\section{INTRODUÇÃO}

O Plano Diretor é uma lei municipal, cuja elaboração está prevista na Constituição Federal de 1988, em seu artigo 182, $\S 1^{\circ}$. É o instrumento básico da política de desenvolvimento e de expansão urbana e veio a ser regulamentada pelo Estatuto da Cidade (Lei $n^{\circ}$ 10.257/2001), que estabelece seu conteúdo mínimo (ARAÚJO JUNIOR, 2006). Tem como objetivo ordenar o pleno desenvolvimento das funções sociais da cidade e garantir o bem-estar de seus habitantes e subsidiar o planejamento e a gestão territorial urbana (BRAGA E CARVALHO, 2001; NASCIMENTO E CAMPOS, 2006).

Deve contemplar diretrizes referentes à circulação, habitação, meio ambiente, patrimônio histórico e outros aspectos relacionados com o desenvolvimento das cidades, de modo a proporcionar melhores condições de vida a sua população, e sua criação deve contar com a participação da comunidade (BRAGA E CARVALHO, 2001; NASCIMENTO E CAMPOS, 2006).

Outras leis municipais poderão tratar da política urbana, mas terão sempre que conformar-se com as diretrizes traçada pelo Plano Diretor para as áreas urbana e rural do município (GALIL, 2005).

E um dos itens previstos para um Plano Diretor completo é a realização de um Plano Diretor de Arborização Urbana (PDAU), um instrumento de planejamento municipal de áreas verdes urbanas. De acordo com a Prefeitura de Porto Alegre (2008), o PDAU é o "conjunto de métodos e medidas adotadas para preservação, manejo e expansão das árvores nas cidades, de acordo com as demandas técnicas e as manifestações de interesse das comunidades locais". Portanto, deve considerar as especificidades locais e atender às demandas da comunidade. Assim, deve ser participativo e normatizar regras para a condução de uma arborização urbana de qualidade. Entretanto, são poucos os municípios brasileiros que possuem tal documento. $E$ alguns daqueles que o possuem ainda não o implantaram, ou não completaram sua efetivação.

Assim, para melhorar e normatizar a arborização das cidades brasileiras foi aprovado no dia 27 de maio de 2008, uma mudança no Estatuto da Cidade, para que seja incluso, obrigatoriamente, nos planos diretores municipais o PDAU, que deverá conter informações sobre espécies e porte das árvores e as condições da arborização em relação à demanda da comunidade (FRENTE PARLAMENTAR AMBIENTALISTA, 2008).

Desta forma, faz-se necessário estudos para investigar qual a situação atual dos PDAUs dos municípios brasileiros. O que vem de encontro com este trabalho que se propõe a apresentar o estado-da-arte dos PDAUs brasileiros, especificamente de Vitória/ES, Porto Alegre/PR, Porto Feliz/SP e Goiânia/GO e realizar uma análise comparativa entre eles. O objetivo é que esta análise ofereça uma visão crítica quanto à elaboração de PDAUs, 
auxiliando na escolha da metodologia, tomada de decisões e diretrizes de novos planos, por meio do estudo e comparação desses planos.

\section{MATERIAIS E MÉTODOS}

A primeira etapa consistiu em uma pesquisa bibliográfica dos planos diretores de arborização existentes e levantamento de dados daqueles que se encontravam disponíveis: inventários, diagnósticos, relatórios, leis, mapas, entre outros. Foi necessário o contato e a consulta a algumas prefeituras, para a obtenção de maiores informações.

Os PDAUs de Porto Alegre/RS, Vitória/ES, Porto Feliz/SP e Goiânia/GO foram escolhidos para análise em face da disponibilidade e acesso às informações. A análise de Porto Alegre será pautada na leitura da lei do plano diretor, já de Goiânia e Vitória, serão examinados os relatórios dos planos na íntegra. O plano de Porto Feliz encontra-se em andamento e será analisado apenas o diagnóstico elaborado a partir do inventário arbóreo da cidade.

Os planos serão analisados comparativamente em termos da metodologia do inventário (quais dados qualitativos e quantitativos foram levantados e como foi feito), do diagnóstico (manipulação dos resultados e conclusões) e das estratégias de planejamento e instrumentos legais adotados. Os resultados desta análise serão organizados em um quadro resumo comparativo.

\section{RESULTADOS E DISCUSSÃO}

\section{Porto Feliz}

O município de Porto Feliz encontra-se a $110 \mathrm{~km}$ da capital São Paulo, em direção leste para oeste do estado. Localiza-se na latitude $23^{\circ} 12^{\prime} \mathrm{S}$ e na longitude $47^{\circ} 31^{\prime} \mathrm{W}$, no bioma Mata Atlântica. Possui uma área total de $557,9 \mathrm{~km}^{2}$ e população de 46.054 habitantes (PORTO FELIZ, 2008; IBGE, 2007)

O "Relatório Preliminar: Diagnóstico da Arborização Urbana do Município de Porto Feliz-SP" (2008) foi o documento disponibilizado pela Prefeitura desta cidade, como um projeto piloto em direção à elaboração do Plano Diretor.

Como já mencionado, este documento é um diagnóstico realizado a partir do primeiro levantamento censitário das árvores nas calçadas e canteiros públicos do centro da cidade. No total foram registradas 161 árvores em 49 ruas visitadas.

As informações levantadas foram características métricas: altura, diâmetro da copa, altura da primeira bifurcação, DAP (Diâmetro a Altura do Peito), sua posição em relação à calçada e à quadra, que permitiu o mapeamento georreferenciado destas; e as 
características qualitativas: espécie, idade média, condição geral da árvore, comportamento das raízes em relação à área de implantação na calçada, conflitos existentes (com rede elétrica, outras árvores, trânsito, edificações, entre outros), necessidades de manejo, como controle fitossanitário, poda leve e pesada, e outras observações como defeito físico por poda, por vandalismo ou provocado por colocação de tutor inadequado.

A partir dos dados levantados in-loco, pode-se traçar um diagnóstico da área, como subsídio para as tomadas de decisão e elaboração do plano diretor de arborização.

Quanto à composição arbórea, foram registradas 24 espécies de um total de 161 indivíduos, sendo que 60,25\% pertencem a duas espécies: Sibipiruna (Caesalpinia pelthophoroides) e Falsa Murta (Murraya paniculata). Foi detectado que das 49 ruas avaliadas $47 \%$ não apresentam arborização. A avaliação da condição geral dos indivíduos quanto à raiz mostrou que $46 \%$ das árvores apresentam alterações no calçamento, devido ao plantio inadequado, mas não evidentes. Os conflitos de todos os tipos estavam presentes em $45 \%$ das árvores, 31\% necessitam de controle fitossanitário e 56\% mostram presença de algum defeito físico. Por fim, é apresentado na Figura 1 o resultado da soma das necessidades de manejo detectadas no levantamento: $84 \%$ dos indivíduos necessitam de alguma atenção ou medida de manejo.

Como considerações finais do relatório é ressaltada a importância deste presente estudo como subsídio na gestão da arborização nos locais avaliados. Além disso, é afirmado que apesar da amostragem ser pequena, já se pode traçar algumas conclusões, como a baixa diversidade - existe uma grande quantidade de indivíduos, mas há grande predominância de apenas duas espécies - o que leva a um quadro de vulnerabilidade a pragas e transmissão de doenças; e muitas ruas não são arborizadas, ou seja, a distribuição arbórea não é homogênea no centro da cidade.

A partir destes resultados foi possível à Prefeitura de Porto Feliz tirar conclusões sobre a necessidade urgente de um plano que norteasse as tomadas de decisões, oferecesse diretrizes em relação às espécies mais adequadas para cada tipo de local, acompanhadas de um cronograma de plantio e técnicas de manejo, qualificação e treinamento da equipe técnica em relação a este manejo e educação ambiental, de modo a sensibilizar a população quanto à conservação da arborização viária urbana. 


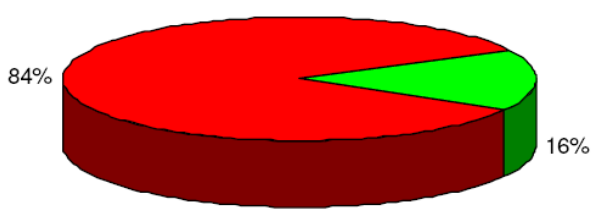

$\square$ Necessitam de Atenção

$\square$ Não Necessitam de Atenção

Figura 1. Porcentagem de indivíduos arbóreos com necessidade de atenção (RELATÓRIO PRELIMINAR, 2008)

\section{Goiânia}

Capital do estado de Goiás, Goiânia possui uma área total de $739 \mathrm{~km}^{2}$, e população de 1.244.645 habitantes (IBGE, 2007). Localiza-se na latitude $16^{\circ} 40^{\prime} \mathrm{S}$ e na longitude $49^{\circ}$ 16 'W, no bioma do Cerrado.

A Prefeitura de Goiânia tem disponibilizado à população seu PDAU 4 na íntegra, cuja estrutura está dividida em 6 partes: histórico da arborização, características da arborização e política atual, cadastramento e diagnóstico, planejamento - subdividido em programa de ampliação e re-qualificação da cobertura vegetal e diretrizes gerais para implantação - e por fim, regimento legal da arborização do município.

Devido ao tamanho da cidade, segundo a Prefeitura de Goiânia, o cadastramento censitário seria muito demorado e custoso, por isso a prefeitura realizou um inventário total (censo) em 70 bairros, que posteriormente serviu como referência para o restante da cidade, ou seja, por meio de técnicas estatísticas os resultados obtidos foram replicados para os bairros em que a arborização não foi avaliada.

$O$ inventário consistiu no cadastramento arbóreo qualitativo e quantitativo acompanhado de mapeamento georreferenciado. A intenção é formar um banco de dados interligado ao MUBGD - Mapa Urbano Básico Digital de Goiânia, que seria constantemente atualizado com plantio e remoção de árvores, e possibilitaria o acesso de qualquer cidadão sobre a situação de uma determinada árvore, fornecendo informações sobre ações de manejo necessárias.

Os dados quantitativos coletados se referem ao número de indivíduos e espécies ocorrentes, número de árvores a serem podadas, removidas e de novos plantios. Conjuntamente foram coletados os dados qualitativos, ou seja, um breve diagnóstico de cada indivíduo arbóreo, contento a descrição sobre porte; condições físico-sanitárias em

\footnotetext{
${ }^{4}$ Plano diretor de arborização urbana de Goiânia. Goiânia: AMMA, 2008. 134 p.
} 
geral; aspectos paisagísticos; conflitos ou interferências possíveis com fiação elétrica, telefonia ou iluminação pública; condição da copa quanto à interferência e poda; características do fuste e das raízes e necessidades de manejo.

Esse tipo de inventário possibilitou pequenas proposições e o direcionamento de algumas ações, com a identificação e mapeamento das necessidades, do tipo de manejo necessário, dos indivíduos a serem removidos e da capacidade de plantio de novas mudas em cada logradouro dos 70 distritos avaliados, conforme segue o exemplo da quadra 65 (Figura 2).

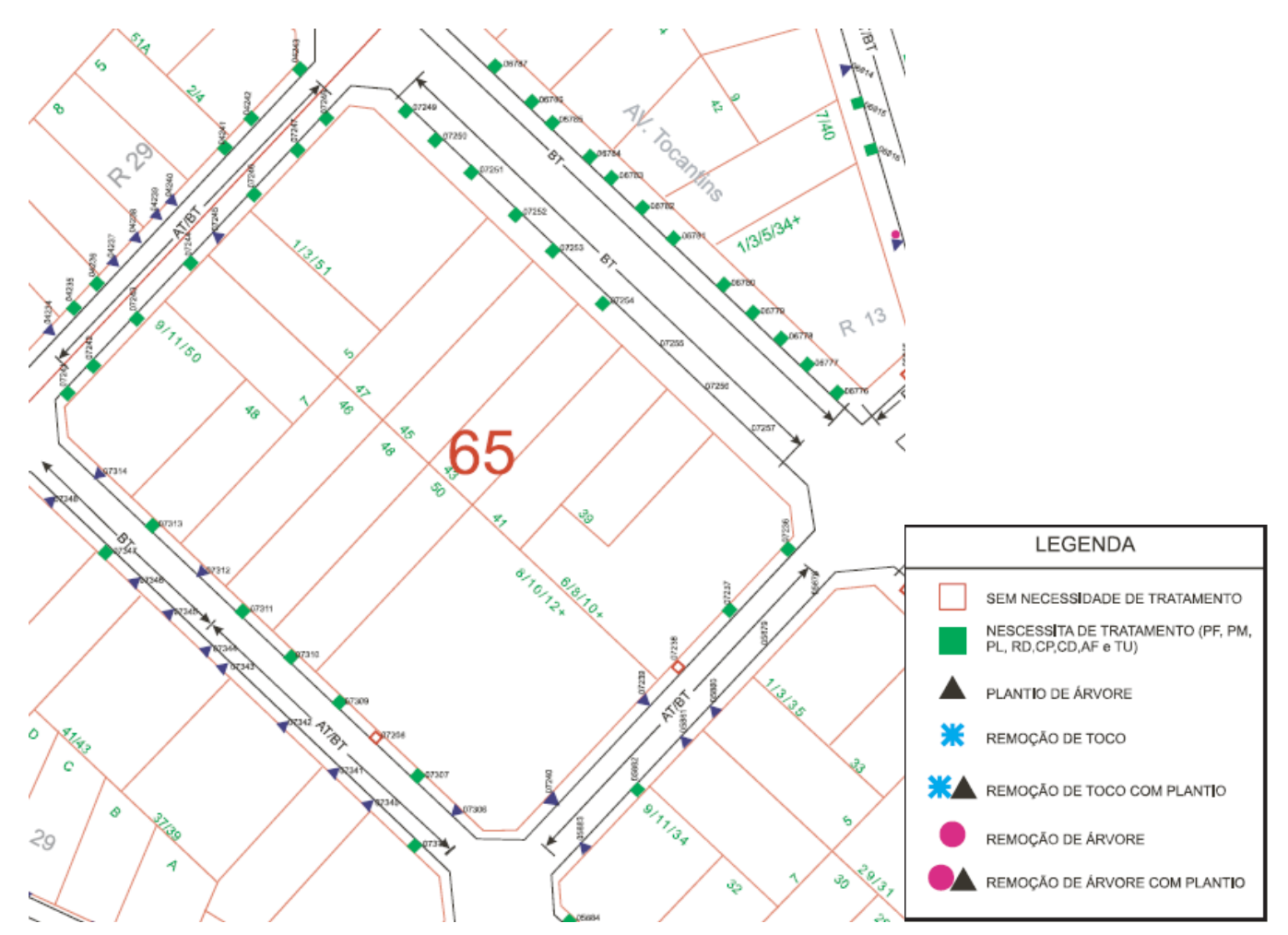

Figura 2. Tabulação do Planejamento Paisagístico

Neste inventário foram cadastrados 178.230 pontos cadastrados e os resultados foram: 130.061 árvores existentes $(74 \%)$ e 38.874 novos plantios (21\%). Das árvores existentes, foi recomendada a remoção de 7.079 correspondendo a $5,32 \%$ do total, a espécie monguba (Pachira aquatica) representava $54 \%$ do total de árvores a serem removidas. Foram identificadas 328 espécies, entretanto a freqüência de ocorrência não é equilibrada, pois duas espécies representam $26 \%$ do total de indivíduos: a monguba, com $19 \%$ e a sibipiruna com $17 \%$. 
De acordo com o PDAU, a avaliação das condições da arborização e a discussão dos resultados são importantes instrumentos, pois permitem a identificação das prioridades de ação, proporcionando a elaboração de cronograma de plantio e manutenção.

A última etapa do plano foi o planejamento, subdividido em dois capítulos. O primeiro discute sobre os impactos positivos e negativos (estes decorrentes de uma arborização mal planejada) e as características da vegetação que afetam diretamente na escolha das espécies, como aspectos morfológicos, funcionais, estéticos e ambientais.

Há um item dentro deste capítulo que trata dos critérios que devem ser considerados na seleção das espécies mais recomendadas para um determinado local, e apresentação de uma lista das espécies que não recomendadas à arborização viária por conta das raízes superficiais e agressivas, da fragilidade quanto ao ataque de pragas, presença de frutos carnosos ou grandes e espécies com princípios tóxicos. Em seguida, é apresentada uma segunda lista de espécies não recomendadas especificamente para os logradouros de Goiânia, face às conclusões tiradas na análise do inventário, como por exemplo, a monguba, devido à grande ocorrência na vias públicas e por ser suscetível ao ataque de um coleóptero; além disso, não é uma espécie nativa, de condições climáticas e edáficas muito diferentes das características de Goiânia. Outro exemplo é a sibipiruna, que apresenta grande ocorrência nos logradouros e estão mais suscetíveis ao ataque dos cupins.

O Plano conta ainda com planejamento paisagístico de 16 setores de Goiânia (dentro daqueles 70 setores inventariados). Ele consistiu na indicação das espécies de árvores a serem plantadas nos locais já diagnosticados no inventário como pontos de novo plantio, considerando-se as características de cada ambiente: largura da rua e calçada, existência de fiação aérea, tubulações subterrâneas, equipamentos urbanos e outras interferências. Foi recomendado o plantio de 24.415 árvores de 151 espécies, priorizando as nativas do cerrado (64\% do total das espécies indicadas), espécies frutíferas voltadas à alimentação da avifauna e exóticas com boa adaptação ao clima e solo da região.

O exemplo a seguir mostra a tabulação da indicação das espécies resultantes do planejamento paisagístico de algumas ruas e avenidas do setor Aeroporto. Para cada rua é identificado seu código, a largura desta e da calçada, a presença ou não de fiação e o tipo: alta tensão (AT) ou baixa tensão (BT). Nesta planilha é indicada uma espécie para cada quadra e a quantidade de indivíduos a serem plantados (Figura 3).

Para os bairros restantes que foram inventariados e não receberam este planejamento paisagístico mais detalhado, recomenda-se que seja realizada uma indicação genérica das espécies, conforme as características do local. Tal proposição pode ser embasada com uma segunda tabela disponível no Plano, com parâmetros referenciais que determinam qual o porte da árvore a ser plantada, em função da presença ou não da rede aérea, recuo, jardim ou estacionamento e largura da calçada.

REVSBAU, Piracicaba - SP, v.3, n.4, p.53-74, 2008 


\begin{tabular}{|c|c|c|c|c|}
\hline AV. L & \multicolumn{2}{|c|}{ LARGURA: $19 \mathrm{M}$} & \multicolumn{2}{|l|}{ CALÇADA: $6 \mathrm{M}$} \\
\hline QUADRA & FIAÇÃO & QDADE. & INDICAÇÃO & OBS. \\
\hline $2 \mathrm{~A}$ & $\mathrm{SF}$ & 16 & Pterogyne nitens Tul. (Amendoim-bravo) & \\
\hline $3 \mathrm{~A}$ & SF & 17 & Platycyamus regnellii Benth. (Folha-de-bolo) & \\
\hline $8 \mathrm{~A}$ & $\mathrm{AT} / \mathrm{BT}$ & 2 & Cordia glabrata (Mart.) DC. (Louro-branco) & Plantar meio calçada \\
\hline $9 \mathrm{~A}$ & $\mathrm{AT} / \mathrm{BT}$ & 1 & Cordia glabrata (Mart.) DC. (Louro-branco) & Plantar meio calçada \\
\hline $10 \mathrm{~A}$ & $\mathrm{AT} / \mathrm{BT}$ & 3 & Cordia glabrata (Mart.) DC. (Louro-branco) & Plantar meio calçada \\
\hline $11 \mathrm{~A}$ & BT & 1 & Cordia glabrata (Mart.) DC. (Louro-branco) & Plantar meio calçada \\
\hline $12 \mathrm{~A}$ & $\mathrm{AT} / \mathrm{BT}$ & 4 & Tapirira guianensis Aubl. (Pau-pombo) & Plantar meio calçada \\
\hline $13 \mathrm{~A}$ & $\mathrm{AT} / \mathrm{BT}$ & 3 & Tapirira guianensis Aubl. (Pau-pombo) & Plantar meio calçada \\
\hline $14 \mathrm{~A}$ & $\mathrm{AT} / \mathrm{BT}$ & 4 & Tapirira guianensis Aubl. (Pau-pombo) & Plantar meio calçada \\
\hline
\end{tabular}

Figura 3. Indicação de espécies de acordo com as características dos locais

Para os bairros não inventariados, o Plano prevê um inventário pré-plantio com a intenção de apresentar uma planilha semelhante ao planejamento paisagístico após visita in-loco. Durante a visita deverá ser preenchida uma ficha de campo contendo as seguintes informações: largura da calçada, existência e tipo de fiação, presença de outros equipamentos públicos, espaçamento entre as árvores, espaço para novos plantios, necessidade de remoção de árvore e tocos, a fim de indicar a espécie mais adequada ao local.

O capítulo VI sobre planejamento traz diretrizes de implantação, ações e programas a serem instituídos e detalhes de gestão da arborização, assemelhando-se quase a um manual técnico. Dentre os programas previstos, estão:

- Criação de grupo de trabalho interdisciplinar a fim de planejar e acompanhar a implantação; outro grupo composto por representantes dos órgãos municipais envolvidos a fim de discutir e propor ações; e um terceiro grupo com representantes de órgãos municipais e instituições, universidades e entidades de classe, para discussões, trocas de conhecimentos, entre outros;

- Convênios: participação e celebração de parceria público-privada para a viabilização de diversos projetos. Além disso, estabelecer parcerias com instituições de ensino para fomentar pesquisas na área de produção de mudas e introdução de espécies nativas do cerrado na arborização urbana;

- Programas de capacitação e qualificação da mão-de-obra para serviços de arborização;

- Programas de Educação Ambiental: para divulgação geral do plano, atuação junto à rede escolar e conscientização ampla da população, considerando questões sócio-culturais e econômicas de diferentes segmentos da sociedade;

- Programa de Cadastramento da Arborização consiste nos inventários com o mapeamento de cada indivíduo arbóreo e as subseqüentes vistorias. Deve ser informatizado, a fim de agilizar a obtenção de dados e resultados; 
- Programa Anual de Plantio: tem como objetivo apresentar programas de plantio a cada ano a serem executados no próximo período chuvoso. Este programa deve diversificar as espécies a serem plantadas, não podendo ser superior a 30 espécies diferentes, sendo que uma espécie não deve atingir mais que 15\% de representatividade. Estabelece um prazo de 10 a 20 anos para que Goiânia tenha uma arborização planejada para cada setor da cidade. Visa dar continuidade ao Programa de Cadastramento e mapeamento de todos os setores e ao estudo da introdução de espécies nativas do cerrado na arborização viária.

- Programa de produção de mudas nativas e exóticas: visa atender à demanda da prefeitura no Programa de Plantio, priorizando a produção de espécies nativas do cerrado. Há um acordo de cooperação técnica com a Escola de Agronomia da Universidade Federal de Goiás, que visa aumentar a produção de mudas de 150 mil para 400 mil por ano;

- Programa de Manutenção: tem como objetivo assegurar o bom desenvolvimento da muda e zelar pela integridade desta e das árvores adultas existentes. Inclui técnicas de poda, correta remoção de árvore, replantio e controle fitossanitário;

- Programa de Substituição Gradativa das árvores da espécie Monguba, devido a sua fragilidade a pragas e falta de adaptação às condições climáticas e edáficas de Goiânia;

- Programa de Monitoramento: visa acompanhar sistematicamente o desenvolvimento das árvores existentes e mudas plantadas;

- Plantio Voluntário: visa dar continuidade ao Programa "Plante a Vida", com ênfase a distribuição de mudas, além de orientação à população quanto às espécies mais recomendadas e adequadas a determinado local;

- Análise da legislação municipal em relação à arborização urbana, propondo alterações na legislação vigente e criação de novas leis.

Por fim, no último capítulo é apresentada a legislação federal e municipal pertinentes à arborização urbana. Porém, não está contida a lei ou a normalização resultante do PDAU. Esta foi obtida através do Diário Oficial da cidade e foi instituída como Instrução Normativa em 05 setembro de 2008. Nesta está contido os objetivos do plano, as diretrizes gerais, a participação da comunidade por meio de educação ambiental, a instrumentação do Plano Diretor (formação dos grupos de trabalho, informações sobre a produção de muda, plantio, manejo e conservação, poda, substituição de indivíduos e espécies) e diretrizes sobre vegetação em áreas particulares.

\section{Vitória}

Capital do estado do Espírito Santo, Vitória é constituída por 34 ilhas e uma região continental, totalizando uma área de $104,3 \mathrm{~km}^{2}$. Localiza-se na latitude sul $20^{\circ} 10^{\prime}$ e longitude 
oeste $40^{\circ} 20^{\prime}$, no bioma Mata Atlântica. Concentra a maior parte das atividades econômicas e culturais da região (Diagnóstico de aspectos prioritários em política de gestão ambiental urbana na rede de mercocidades, 2002). Possui uma população de 314.042 habitantes (IBGE, 2007).

Sua malha urbana é marcada por falta de espaço físico, calçadas e ruas estreitas, que se constituem fatores limitantes para uma arborização urbana de qualidade. Por meio da observação destes e outros problemas, a Prefeitura do Município de Vitória decidiu realizar o "Plano Diretor de Arborização Urbana e Áreas Verdes", no ano de 1992, que é dividido em quatro capítulos mais anexos. Documento este que será analisado neste trabalho.

No capítulo I Diagnóstico e Caracterização Geral do Município, a vegetação é dividida em Arborização de Ruas, Áreas Verdes Públicas, Áreas Verdes Particulares e Unidades de Conservação. Cada uma dessas áreas é analisada separadamente. Nesse trabalho optou-se por dar ênfase à Arborização de Ruas.

Para o diagnóstico da Arborização de Ruas realizou-se um inventário quantitativo total e um inventário qualitativo por amostragem. O formulário utilizado para o inventário qualitativo foi baseado naqueles utilizados em Curitiba (1984), Recife (1985) e Maringá (1988).

As informações coletadas referiam-se à: identificação da amostra; identificação da espécie; porte da árvore (altura, altura da primeira ramificação, CAP e diâmetro de copa); qualidade (condição geral da árvore e raízes); posição de plantio; planejamento (compatibilização entre o porte da espécie utilizada e o espaço disponível para plantio); necessidades de manejo; e verificação de existência de dano físico por vandalismo ou acidente, por poda, tutoramento, obras de construção e identificação quando plantio irregular e quando frutífera.

Dentre alguns resultados está a distribuição irregular dos 22.208 indivíduos arbóreos existentes, representados por 73 espécies. $E$ apenas $35 \%$ da área urbanizada da cidade pode ser considerada como arborizada, $31 \%$ apresenta-se parcialmente arborizada, e $34 \%$ sem qualquer arborização.

Ainda na fase de diagnóstico foi calculado um Índice de Áreas Verdes (área em $\mathrm{m}^{2}$ por habitante) para cada divisão proposta. Para a Arborização de Ruas obteve-se 2,88 $\mathrm{m}^{2} / \mathrm{hab}$.

O Plano conclui o diagnóstico indicando que a implementação e o acompanhamento do Plano serão efetivados pela Secretaria Municipal do Meio Ambiente (SEMMAM) e pela Secretaria Municipal de Serviços Urbanos (SEMURB).

Os inventários realizados chegaram em resultados de grande importância para a caracterização da situação atual da arborização na cidade, como qual a distribuição das 
mesmas, qual a quantidade de indivíduos que necessitam de poda ou algum controle fitossanitário. Facilitando a localização dessas árvores, permitindo uma melhor manutenção dessas áreas.

No capítulo II, são definidas propostas, com base no diagnóstico, para cada divisão realizada.

Assim, deve ser realizado um novo inventário para indicar ou restringir o plantio, respeitando o número máximo de $15 \%$ de participação por espécie. E para o plantio, deverá ser considerado o fator paisagístico/estético. Também indica quais características as árvores devem ter para serem priorizadas no plantio, como espécies com raízes de crescimento em profundidade, qual a altura ideal da muda, a sua área necessária para crescimento, dentre outros. Além disso, dá ênfase a campanhas informativas e educativas para minimizar os danos ocorridos nos espécimes.

Entretanto a localização de áreas para plantio já poderia ter sido realizada, por exemplo, com o auxílio da ficha de campo para indicação e localização de plantio a utilizada em SILVA FILHO (2002).

No capítulo sobre Diretrizes Gerais de Ordem Técnica são estabelecidos programas e projetos para que as propostas sejam efetivamente implantadas, definindo os objetivos e atividades para cada um. E foram definidos os seguintes programas:

- Programa de Plantio: tem como objetivos realizar o levantamento das características físicas dos bairros a serem arborizados e definir ruas a serem arborizadas, assim como as posições de plantio e o número de mudas necessárias. E assim implantar a arborização de ruas de acordo com normas técnicas adequadas e definir cronograma de ação, estabelecendo metas anuais a serem cumpridas;

- Programa de Manutenção: visa manter a boa condição fitossanitária da arborização, assegurar o normal desenvolvimento das mudas e aprimorar técnicas de realização de poda através do treinamento das equipes. Também pretende estabelecer convênios entre diversos atores da sociedade para a regulamentação da execução de podas;

- Programa de Monitoramento: pretende acompanhar sistematicamente o desenvolvimento das árvores plantadas nas ruas e avenidas e obter informações periódicas, que sirvam de base para posterior replanejamento.

Para o âmbito geral do Plano, foram estabelecidos os seguintes programas:

-Programa de Cadastramento: para obter um sistema cadastral e organizar os dados obtidos em vistorias e inventários, de modo a computá-los no contexto geral e considerálos para futuras ações de planejamento/replanejamento;

- Programa de Desenvolvimento do Horto Municipal: visa assegurar a produção qualiquantitativa de mudas;

REVSBAU, Piracicaba - SP, v.3, n.4, p.53-74, 2008 
- Programa de Educação Ambiental: pretende desenvolver práticas de ação pública esclarecedoras da importância da arborização, estimular a participação da comunidade, para assim diminuir níveis de vandalismo.

Nas Diretrizes Gerais de Ordem Político-Institucional, foram estabelecidos dois programas, com seus objetivos e atividades descritos: Programa de Pesquisa, Capacitação Técnica e Cooperação, visando convênios entre diversos atores da sociedade e a Prefeitura do Município e Programa de Revisão e Aperfeiçoamento da Legislação.

Nos anexos do Plano está o Projeto de Lei do Plano Diretor de Arborização e Áreas Verdes. Define os objetivos (proteção, fiscalização e recuperação; elevação do índice de área verde; monitoramento; instituição de programas educativos; estudo de espécies; implantação, preservação, fiscalização e recuperação de unidades de conservação; e proteção dos morros e encostas); atribuições da SEMMAM e da SEMURB; regras para manutenção, implantação e plantio de árvores; e penalidades nos casos de dano, derrubada não autorizada ou morte provocada de árvores.

Este Projeto de Lei foi aprovado na reunião do CONDEMA - Conselho Municipal de Defesa do Meio Ambiente, Resolução 002/92, de 10/08/92, em Vitória/ES.

Apesar de um Plano bem estruturado, com metas e programas estipulados, 0 mesmo não foi colocado em prática, já que, em contato com a SEMMAM, a mesma disse não ter conhecimento sobre o plano.

Entretanto, notícias publicadas no portal da prefeitura ("Vitória adota medidas para garantir a arborização), em 19 de setembro de 2008 e na Gazeta On-line ("Vitória arborizada garante bem estar da população"), em 21 de setembro de 2008, mostram a retomada deste plano, e a tendência para que o mesmo seja atualizado.

Além disso, na Lei municipal n 6282/2005, que dispõe sobre alterações na estrutura organizacional do Município de Vitória, no anexo XVI, o item 5 incumbe à Secretaria Municipal de Meio Ambiente "Executar o Plano Diretor de Arborização e Áreas Verdes e promover sua avaliação, atualização e adequação", demonstrando a preocupação do Município em retomar este Plano.

\section{Porto Alegre}

A cidade de Porto Alegre possui uma área total de $476,30 \mathrm{~km}^{2}$, sendo que o continente corresponde a $431,85 \mathrm{~km}^{2}$ e as ilhas a $44,45 \mathrm{~km}^{2}$, é a capital do Rio Grande do Sul. Situada na latitude $30^{\circ} 05^{\prime} \mathrm{S}$ e na longitude $51^{\circ} 10^{\prime} \mathrm{W}$, no bioma Mata Atlântica (PORTO ALEGRE, 2008). Com uma população de 1.420.667 habitantes (IBGE, 2007). 
Foi um dos primeiros municípios brasileiros a instituir um PDAU. Vindo a obter sua formatação legal e atualizada em novembro de 2006, por meio da Resolução COMAM n 05 publicado no Diário Oficial do Município. Resolução a qual será analisada neste trabalho.

De acordo com este documento, o PDAU pretende ser uma política de plantio, preservação, manejo e expansão da arborização na cidade.

Quanto aos objetivos do Plano estão: a definição de diretrizes de planejamento, implantação e manejo da arborização urbana; a promoção da arborização como instrumento de desenvolvimento urbano e qualidade de vida; implementação e manutenção da arborização; estabelecimento de critérios de monitoramento; e o envolvimento da população neste processo.

A execução do Plano deverá ser realizada pela Secretaria Municipal do Meio Ambiente (SMAM), nas questões relativas à elaboração, análise e implantação de projetos e manejo da arborização urbana.

No inciso IV, do artigo $5^{\circ}$ do capítulo IV, se estabelece de que os passeios públicos deverão ter no mínimo $40 \%$ de área vegetada. Além deste, outros parâmetros são determinados, como utilização de cabos ecológicos pelas companhias de energia elétrica.

Essa resolução regulamenta a necessidade de se utilizar predominantemente espécies nativas regionais, num percentual mínimo de $70 \%$. Sendo vedado o plantio de espécies exóticas invasoras.

Além da identificação das espécies que compõem a arborização, o Plano prevê a informatização de todas as ações, dados e documentos referentes a este tema, para assim manter um cadastro permanente e atualizado, mapeando todos os elementos arbóreos existentes.

Compete também à SMAM desenvolver programas de Educação Ambiental para o envolvimento e comprometimento da população na elaboração, implantação e manutenção do Plano. Bem como elaborar convênios com instituições públicas e privadas visando agilizar e facilitar a busca por recursos para a efetivação do Plano.

Quanto à instrumentação do Plano, o viveiro municipal será responsável pela produção de mudas, identificação e cadastro de árvores-matrizes. Dá instruções quanto aos procedimentos que devem ser tomados para o plantio correto da muda (como a distância entre as árvores e dimensões da cova). E incumbe ao proprietário do imóvel a construção de um canteiro em torno de cada árvore de seu lote, atendendo a critérios específicos.

Prevê um programa de manutenção, com visitas periódicas, principalmente nos primeiros meses do plantio da muda e priorizando o atendimento preventivo, evitando atividades drásticas, como podas pesadas. Além disso, prevê capacitação permanente da mão-de-obra, para a realização dessa manutenção.

REVSBAU, Piracicaba - SP, v.3, n.4, p.53-74, 2008 
Dedica uma Seção ao Plano de Manejo, que deverá atender objetivos específicos: unificar a metodologia de trabalho nos diferentes setores da SMAM; diagnosticar a população de árvores da cidade por meio de inventário quali-quantitativo, mapeando o local e a espécie na forma de cadastro informatizado; elencar as espécies a serem utilizadas, de acordo com as zonas definidas; estabelecer critérios técnicos de manejo preventivo da arborização urbana; e identificar áreas potenciais para novos plantios.

Quanto ao estado atual de implementação do Plano, em contato com o engenheiro agrônomo Luiz Antonio Piccoli, coordenador do PDAU da cidade, foi informado que as regras do mesmo estão sendo aos pouco incorporadas. O grande fator positivo que já se conseguiu foi o convencimento das autoridades quanto às especificações necessárias para o plantio de mudas, conseguindo verbas para tal atividade. Já a maior dificuldade está em consegui-las num tamanho padrão. O inventário na cidade já foi realizado, entretanto não tivemos acesso ao mesmo.

De acordo com uma reportagem realizada pelo Ministério das Cidades ("Plano Diretor quer deixar Porto Alegre mais arborizada"), de 30 de setembro de 2007, a SEMAM possui uma meta de plantio de 10.000 árvores por ano.

\section{Análise Comparativa}

Nesta etapa pretende-se analisar os Planos Diretores de Arborização Urbana descritos acima, sem deixar de considerar as peculiaridades de cada um e, quando necessário, essa apreciação será feita individualmente. O objetivo é que essa reflexão venha contribuir e enriquecer a discussão sobre os planos diretores, proporcionando oportunidade para melhoria contínua e evidenciando os pontos fortes, estratégias e medidas bem sucedidas.

A análise está organizada e segue a estrutura geral dos Planos Diretores de Arborização: inventário (coleta de dados); diagnósticos, ou seja, como esses dados foram trabalhados e quais os resultados conclusivos que foram extraídos; e planejamento. $O$ inventário foi subdividido em tipo - total (censo) ou amostral, informações coletadas in-loco e se houve a plotagem em mapas dessas informações. O planejamento foi subdividido em programas implantados, se apresentam diretrizes técnicas de plantio e manejo, cronograma, projeto de lei ou instrumentação legal e mapa de zoneamento. O compilamento dessas informações foi agrupado em um quadro comparativo dos Planos Diretores de Arborização que auxiliou a análise (Quadro 1).

Como já mencionado, o PDAU de Porto Feliz está em andamento e o de Porto Alegre foi possível apenas a obtenção da lei, por isso, não se preencheu todos os quesitos do quadro resumo. 


\begin{tabular}{|c|c|c|c|c|c|}
\hline Etapa & Cidade & Porto Feliz & Goiânia & Vitória* & Porto Alegre \\
\hline \multirow{3}{*}{ 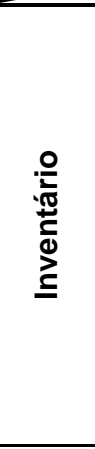 } & Tipo & Censo (regional) & Amostral & Censo e Amostral & Não disponibilizado \\
\hline & Dados & $\begin{array}{l}\text {-Espécie; } \\
\text {-Idade aproximada; } \\
\text {-Porte; } \\
\text {-Condições gerais; } \\
\text {-Comportamento das raízes; } \\
\text {-Área livre permeável; } \\
\text {-Condições / controle fitossanitário; } \\
\text {-Necessidade de poda; } \\
\text {-Defeitos; } \\
\text {-Conflitos / interferências. }\end{array}$ & $\begin{array}{l}\text {-Espécie; } \\
\text {-Porte; } \\
\text {-Condições gerais; } \\
\text {-Condições / controle fitossanitário; } \\
\text {-Necessidade de poda e remoção; } \\
\text {-Conflitos / interferências; } \\
\text {-Raízes: condições e interferências; } \\
\text {-Fuste: condições; } \\
\text {-Aspectos paisagísticos. }\end{array}$ & $\begin{array}{l}\text {-Localização; } \\
\text {-Espécie; } \\
\text {-Porte; } \\
\text {-Condição geral da árvore; } \\
\text {-Condição das raízes; } \\
\text {-Posição de plantio; } \\
\text {-Planejamento (relação entre } \\
\text { porte e espaço físico); } \\
\text {-Necessidade de manejo; } \\
\text {-Danos. } \\
\end{array}$ & Não disponibilizado \\
\hline & Mapeamento & Sim & Sim & Sim & Sim \\
\hline 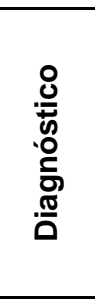 & Resultados & $\begin{array}{l}\text {-Grau de diversidade; } \\
\text {-Taxa de distribuição arbórea ao } \\
\text { longo das ruas; } \\
\text {-\% de árvores com necessidade de } \\
\text { manejo; } \\
\text {-\% de árvores com necessidade de } \\
\text { atenção. }\end{array}$ & $\begin{array}{l}\text {-Grau de diversidade; } \\
\text { - relação da \% de queda com a } \\
\text { adaptabilidade da espécie; } \\
\text { - \% Árvores com necessidade de } \\
\text { manejo; } \\
\text {-\% da origem das espécies; } \\
\text {-\% frutíferas para fauna e ser humano; } \\
\text {-\% remoção de arvores. }\end{array}$ & $\begin{array}{l}\text {-Quantidade, distribuição e } \\
\text { composição da arborização; } \\
\text {-Qualidade das árvores; } \\
\text {-Características dos plantios; } \\
\text {-Árvores com necessidade de } \\
\text { manejo; } \\
\text {-índice de áreas verdes. }\end{array}$ & \\
\hline \multirow{5}{*}{ 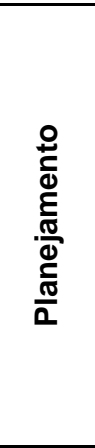 } & Programas & Não possui & $\begin{array}{l}\text { Plantio; Manejo; Monitoramento; } \\
\text { Educação Ambiental; Cadastramento; } \\
\text { Capacitação e Qualificação da mão-de- } \\
\text { obra; Produção de mudas; Plantio } \\
\text { Voluntário; Convênios; Substituição da } \\
\text { espécie Monguba. }\end{array}$ & $\begin{array}{l}\text { Plantio, Monitoramento e } \\
\text { Manutenção; de Cadastramento, } \\
\text { de Desenvolvimento do Horto } \\
\text { Municipal e Educação Ambiental; } \\
\text { Convênios. }\end{array}$ & $\begin{array}{l}\text { Plano de Manejo; } \\
\text { Manutenção; Capacitação e } \\
\text { qualificação da mão-de-obra; } \\
\text { Programa de Educação } \\
\text { Ambiental; Convênios }\end{array}$ \\
\hline & $\begin{array}{l}\text { Técnicas de } \\
\text { plantio e manejo }\end{array}$ & Não possui & Sim & $\operatorname{Sim}$ & Sim \\
\hline & $\begin{array}{l}\text { Instrumentos } \\
\text { legais }\end{array}$ & Não possui & $\begin{array}{l}\text { AMMA Instrução Normativa } n^{\circ} 30 \text {, } \\
05 / 09 / 2008\end{array}$ & Resolução CONDEMA nº 002/92 & $\begin{array}{l}\text { Resolução COMAM nº } \\
\text { 05/2006 }\end{array}$ \\
\hline & Cronograma & Não possui & Não possui & Para alguns itens & Não disponibilizado \\
\hline & Zoneamento & Não possui & Não possui & Não possui & $\operatorname{Sim}$ \\
\hline
\end{tabular}

Quadro 1. Resumo Comparativo dos Planos Diretores de Arborização Urbana. 
Inventário

Observa-se que as variáveis qualitativas e quantitativas adotadas para o levantamento de dados do inventário são semelhantes em quase todos os planos diretores analisados e úteis para um diagnóstico final. Entretanto faz-se necessário algumas considerações quanto à metodologia adotada em cada um deles.

Devido ao fato do Plano de Porto Feliz estar em andamento e ainda se mostrar como um projeto piloto apenas para os bairros centrais, o inventário total da arborização viária foi viável, pois os objetivos de se cadastrar as árvores ali presentes foram atingidos.

Já para Vitória, uma cidade de porte maior, foi adotado o inventário total em relação aos dados quantitativos e inventário amostral para os dados qualitativos. Sendo que, o levantamento deste último foi aplicado somente nos bairros com mais de $50 \%$ de ruas arborizadas. Tal decisão pode levar a resultados tendenciosos ou distantes da realidade, uma vez que não se escolheu parcelas amostrais heterogêneas, cobrindo uma variedade maior de tipologias ou graus de arborização diferentes. Neste caso, é mais aconselhável um inventário sistemático com unidades amostrais presentes em bairros tanto arborizados quanto não arborizados.

Caso semelhante ocorreu em Goiânia, onde foi realizado inventário total (dados qualitativos e quantitativos) para 70 setores, cujos resultados serviram de levantamento amostral para o restante da cidade, ou seja, os dados foram trabalhados e com uso de técnicas estatísticas aplicados para os bairros que não foram inventariados. Entretanto, estes 70 distritos pertencem a uma mesma região (centro) e são bairros adjacentes, que durante o processo de urbanização foram marcados por uma mesma política de arborização e apresentam, de forma geral, segundo o próprio plano diretor de arborização, uma configuração homogênea. Assim, replicar os mesmo resultados do inventário total para outras regiões pode também incorrer em erros, pois considerando a cidade como um todo, as regiões apresentam dinâmicas e conformações diferenciadas, que reflete em uma arborização qualitativa e quantitativamente distinta. $O$ ideal é que as parcelas amostrais não estejam localizadas em uma região única, como foi feito.

Um ponto positivo no inventário de Goiânia foi a decisão de indicar, no momento de cadastramento das árvores existentes, pontos potenciais e viáveis para novos plantios, seja porque havia um espaço vazio ou porque seria necessária a remoção de uma determinada árvore. Essa medida funciona como uma proposição inicial ao planejamento paisagístico e poupa tempo e recursos, uma vez que não será necessário, pelo menos por um determinado período, um novo inventário para indicação de novos pontos de plantio, como está previsto para Vitória.

Quanto ao mapeamento, todos os planos buscaram o georreferenciamento dos pontos levantados, o que é muito positivo, pois a partir da localização exata deste, é possível elaborar 
planos e projetos paisagísticos mais detalhados, evitando conflitos e possíveis compatibilizações futuras no momento da execução de ações.

\section{Diagnóstico}

Nesta etapa, os resultados observados pelos Planos foram de fundamental importância para subsidiar propostas e conhecer as necessidades de projetos e programas em diversas áreas.

Um desses pontos fundamentais foi a constatação do grau de diversidade de espécies de cada cidade. Todas as cidades apresentaram essa informação, importante para o manejo das árvores na cidade e para aumentar o número de espécies daquelas que não são contempladas e diminuir gradativamente a quantidade de indivíduos de espécies que ultrapassam os limites recomendados.

A taxa de necessidade de manejo, com a classificação do tipo de manejo necessário, também se configura num ponto essencial de todos os Planos. A cidade de Porto Feliz apresenta um ponto forte em relação às outras, pois além de classificar, gerou um gráfico final, provando que $84 \%$ das árvores necessitam de alguma atenção. O que demonstra a questão de urgência de um plano diretor que regularize a situação, funcionando como uma estratégia de sensibilização das autoridades e também da população em geral, o que pode gerar um sentimento de cuidado em relação às árvores, e a arrecadação de recursos para o manejo das mesmas.

A cidade de Vitória se destacou nessa fase por apresentar resultados precisos, organizados por categorias (unidade amostral e espécie), facilitando a elaboração de diretrizes para cada região e para cada espécie, o que acarreta na geração de um zoneamento mais consistente. Pois há informação sobre o bairro, quais os principais problemas do mesmo e as características de sua arborização, e também, sobre cada espécie, quais as mais adaptadas, quais aquelas que mais necessitam de manejo.

Já a cidade de Goiânia se destacou por apresentar a relação entre queda de árvore e adaptabilidade das espécies, como no caso da monguba. Esta análise pode ser útil na tomada de decisões, sobre qual espécie não deve ser utilizada na arborização viária e na criação de programas que incentivem o plantio de novas espécies, principalmente de nativas.

Quanto a Porto Alegre, não foi possível fazer inferências sobre seu diagnóstico, já que seu Plano Diretor de Arborização não foi disponibilizado

\section{Planejamento}

Com relação aos programas previstos nos planos de Goiânia e Vitória, pode-se dizer que há muitas semelhanças entre eles no que se refere ao tema e aos objetivos principais. Ambos contemplam programa de plantio, de manejo, de manutenção, monitoramento, de educação Ambiental, viveiros municipais para a auto-sustentabilidade na produção de mudas,

REVSBAU, Piracicaba - SP, v.3, n.4, p.53-74, 2008 
estabelecimento de convênios e cadastramento informatizado. Entretanto detalhes de como eles serão realizados ainda é um ponto falho; o plano de Vitória, em algumas ações se apresenta mais consolidado neste sentido. Quanto à criação de parcerias e convênios com empresas privadas, instituições de ensino e pesquisa, não é proposto nenhum instrumento legal, como isenção de impostos, que legitime, beneficie ou estimule a parceria.

De acordo com a Resolução COMAM n 05/2006, no PDAU de Porto Alegre, está contemplado o plano de manejo, programa de manutenção, capacitação e qualificação da mão-de-obra, programa de educação ambiental e estabelecimento de convênio. Por estar apenas disponibilizado o documento da lei, não é possível aferir se há outros programas envolvidos e nem como eles serão desenvolvidos.

O Plano de Goiânia inclui, como uma das atividades de novos plantios e educação ambiental, o plantio voluntário através Programa "Plante a Vida". Se por um lado, ele pode ser muito positivo em termos de conscientização da população, por outro, deve-se atentar ao risco do não atendimento às diretrizes estabelecidas pelo mesmo. Essa ação deve ser muito bem orientada ou direcionada para não provocar uma arborização de má qualidade. $\mathrm{E}$ mesmo que o plantio não seja viário, o plantio voluntário deve ser dirigido por técnico para escolha da espécie adequada e técnicas de manejo.

O programa de substituição gradativa das árvores da espécie Monguba (Pachira aquatica) se mostra como uma ação positiva, pois visa, em longo prazo, promover maior diversidade na arborização viária com priorização de espécies nativas do cerrado, controlando a disseminação de pragas e prevenindo futuras quedas acidentais e transtornos na cidade.

Os Planos de Goiânia, Vitória e Porto Alegre apresentam uma grande quantidade de informação técnica traduzidas em regras e critérios em relação ao manejo, que é um ponto muito positivo, pois são de extrema importância na padronização e garantia de qualidade das atividades. Porém, não há a necessidade de que tais informações estejam contidas no Plano Diretor de Arborização Urbana, pois elas podem ser abordadas no manual técnico específico em anexo, de forma a facilitar a leitura do plano e o enfoque aos diferentes segmentos de leitores.

Além disso, para Plano de Goiânia e futuro plano de Porto Feliz, recomenda-se constar em anexo o projeto de lei, que institui seus respectivos Planos Diretores de Arborização Urbana.

Vale ressaltar também como oportunidade de melhoria a todos os planos, que estabeleçam um cronograma como ferramenta de planejamento temporal das atividades propostas, de forma a guiar e a viabilizar a captação de recursos, a gestão e execução das ações. Esse cronograma não necessita ser detalhado, mas deve abranger todas as fases previstas no plano. Goiânia apenas apresenta meta de arborização planejada para toda a cidade em um intervalo de tempo de 10 a 20 anos, o que ainda se mostra muito vago. Já 
Vitória apresenta cronograma apenas para alguns projetos, como por exemplo, cronograma de plantio, baseado no calculo do tempo de execução das atividades e disponibilidade de recursos atuais.

A cidade de Goiânia já possui um planejamento paisagístico. Desta maneira, sugere-se a elaboração de um mapa com esse planejamento e zoneamento e que este fique disponível em seu Plano Diretor, para viabilizar o melhor entendimento deste. Para as outras cidades, faz-se importante a realização desse planejamento paisagístico. Este não precisa estar necessariamente contido no Plano, entretanto as diretrizes de como este planejamento deve ser realizado deverão estar descritas, com informações sobre definição espacial (por bairros ou por macro-regiões), quais as etapas e o cronograma a ser seguido, por exemplo.

Quadro 2. Resumo dos Pontos Fortes e Oportunidades de Melhoria

\begin{tabular}{|l|l|l|}
\hline \multicolumn{1}{|c|}{ Cidade } & \multicolumn{1}{|c|}{ Pontos Fortes } & \multicolumn{1}{c|}{ Oportunidades de Melhoria } \\
\hline Porto Feliz & $\begin{array}{l}\text { - \% de árvores com necessidade de } \\
\text { atenção }\end{array}$ & $\begin{array}{l}\text { - Complementação do Inventário; } \\
\text { - Cronograma; } \\
\text { - Dar seguimento ao Plano; }\end{array}$ \\
\hline \multirow{5}{*}{ Goiânia } & $\begin{array}{l}\text { - Planejamento Paisagístico; } \\
\text { - Relação adaptabilidade e queda. }\end{array}$ & $\begin{array}{l}\text { - Complementação do Inventário; } \\
\text { - Cronograma; } \\
\text { - Disponibilizar legislação; } \\
\text { - Detalhamento dos Programas; } \\
\text { - Mapa de zoneamento. }\end{array}$ \\
\hline \multirow{2}{*}{ Porto Alegre } & $\begin{array}{l}\text { - Diagnóstico preciso; } \\
\text { - Programas bem descritos; }\end{array}$ & $\begin{array}{l}\text { - Planejamento Paisagístico; } \\
\text { - Complementação do Inventário; } \\
\text { - Legislação referente ao Plano. } \\
\text { - Atualizar o Plano. }\end{array}$ \\
& - Legislação atualizada & $\begin{array}{l}\text { - Disponibilizar Plano Diretor de } \\
\text { Arborização; }\end{array}$ \\
\hline
\end{tabular}

\section{CONSIDERAÇÕES FINAIS}

Cada Plano, como pode ser observado, possui seus pontos de excelência e pontos ainda a serem aprimorados para que sua implantação resulte numa arborização de qualidade e que atenda às demandas de cada comunidade.

Assim, a cidade de Porto Alegre poderia disponibilizar o seu Plano Diretor de Arborização para a população, propiciando desta forma, um maior contato da mesma com esse documento e a oportunidade de estudos completos sobre essa temática.

Goiânia deve disponibilizar a lei que institui seu Plano Diretor de Arborização, para que o mesmo seja regulamentado e oficializado. Quanto ao seu Plano, este poderia ser mais sintético e objetivo.

REVSBAU, Piracicaba - SP, v.3, n.4, p.53-74, 2008 
Por se tratar de um Plano feito no ano de 1992, Vitória necessita atualizar e revisar o mesmo, bem como dar andamento ao planejamento paisagístico com zoneamento dos bairros. Porto feliz deve dar andamento ao inventário para toda a cidade e aproveitar as críticas aos Planos estudados para que não cometa os mesmo erros, analisando também a possibilidade de aplicar as medidas bem sucedidas de outros planos para sua cidade.

Uma falha observada nos Planos analisados, foi a falta de participação da comunidade na elaboração do mesmo. O único PDAU que considerou de alguma maneira a população foi o de Goiânia, entretanto, somente a título de entrevista para ilustrar o mesmo. Entende-se que o sucesso e a eficácia do plano diretor dependem da aceitação e envolvimento da população. Assim faz-se necessária a atuação desta em todas as etapas do Plano, desde sua elaboração, levantando as expectativas e as demandas da comunidade, até sua implementação e monitoramento.

Também seria muito útil e interessante se cada cidade fizesse um documento à parte com as discussões e estudos prévios realizados para a elaboração do Plano, contendo as referências para o mesmo.

Os Planos estudados se encontram em diversos estágios, alguns implementados, outros esquecidos e outros em fase de elaboração, revelando incertezas e descompassos, e demonstrando a necessidade de mais estudos e discussões nesta área, a fim de subsidiar novos Planos e impedir erros recorrentes e falhas observadas nos Planos existentes.

\section{REFERÊNCIAS BIBLIOGRÁFICAS}

ARAUJO JUNIOR, M. E. Algumas considerações sobre o plano diretor dos municípios e sua importância no processo de construção da cidadania e da democracia. Revista do Direito

Público da Universidade Estadual de Londrina, Londrina: UEL v.1, n.1, 2006, p. 1-20.

CARVALHO, Pompeu F. de; BRAGA, Roberto (orgs.) Perspectivas de Gestão Ambiental em Cidades Médias. Rio Claro: LPM-UNESP, 2001. pp. 95 a 109.

Diagnóstico de aspectos prioritários em política de gestão ambiental urbana na rede de mercocidades. Montevidéu: SEMA/IDRC, 2002. 166 p. Disponível em: <http://www.idrc.ca/uploads/user-S/11436513501LIVRO.pdf>. Acesso em 25 set 2008.

Diário de Vitória - "Vitória adota medidas para garantir arborização". Disponível em <http://www.vitoria.es.gov.br/diario/2008/0919/arvores2.asp>. Acesso em 25 set 2008.

GALIL, A. M. G. O direito urbanístico no Brasil: aspectos estratégicos para a elaboração do plano diretor. Centro de Pesquisas Estratégicas "Paulino Soares", Juiz de Fora: UFJF, nov 2005, 20 p. 
Frente Parlamentar Ambientalista. Disponível em <http://frenteambientalista.com.br/meioambiente-aprova-plano-de-arborizacao-urbana/>. Acesso em 30 set 2008.

Gazeta On-line - "Vitória arborizada garante bem estar da população". Disponível em <http://gazetaonline.globo.com/index.php?id=/local/minuto_a_minuto/local/materia.php\&cd_ma tia=20154>. Acesso em 25 set 2008.

IBGE - Instituto Brasileiro de Geografia e Estatística. Disponível em <http://www.ibge.gov.br>. Acesso em 20 set 2008.

NASCIMENTO, D. T. N. \& CAMPOS, E. T. Instrumentos de planejamento territorial urbano: plano diretor, estatuto da cidade e a agenda 21. In: CONGRESSO BRASILEIRO DE CADASTRO TÉCNICO MULTIFINALITÁRIO, 2006, Florianópolis, 10 p.

Plano diretor de arborização e áreas verdes. Vitória: PMV/SMMA/SMSV, 1992. 98 p.

Plano diretor de arborização urbana de Goiânia. Goiânia: AMMA, 2008. 134 p.

Ministério das Cidades, Plano Diretor quer deixar Porto Alegre mais arborizada. Disponível em <http://www.cidades.gov.br/secretarias-nacionais/programas-urbanos/Imprensa/planodiretor/noticias-2007/setembro/plano-diretor-quer-deixar-porto-alegre-mais-arborizada/>.

Acesso em 10 set 2008.

Prefeitura de Goiânia. Disponível em <http://www.goiania.go.gov.br/>. Acesso em 30 set 2008

Prefeitura Municipal de Porto Alegre. Disponível em <http://www.portoalegre.rs.gov.br/>. Acesso em 15 set 2008.

Prefeitura Municipal de Porto Feliz. Disponível em <http://www.portofeliz.sp.gov.br>. Acesso em 30 set 2008.

Relatório preliminar: diagnóstico da arborização urbana do município de Porto Feliz - SP. Porto Feliz: Secretaria de Meio Ambiente, 2008. 24 p.

Resolução COMAM - Conselho Municipal de Meio Ambiente n. 05/2006, dispõe sobre o Plano Diretor de Arborização Urbana de Porto Alegre. Disponível em: <http://lproweb.procempa.com.br/pmpa/prefpoa/smam/usu_doc/resolucaoo_5_comam_republi cacao_final.pdf>. Acesso em 15 set 2008.

SILVA FILHO, D. F. Cadastramento informatizado, sistematização e análise da arborização das vias públicas da área urbana do município de Jaboticabal, SP. 2002, $81 f$. Dissertação (Mestrado em Agronomia) - Faculdade de Ciências Agrárias e Veterinárias, Universidade Estadual Paulista, Jaboticabal.

Vitória On Line. Disponível em <http://www.vitoria.es.gov.br>. Acesso em 15 set 2008.

REVSBAU, Piracicaba - SP, v.3, n.4, p.53-74, 2008 